
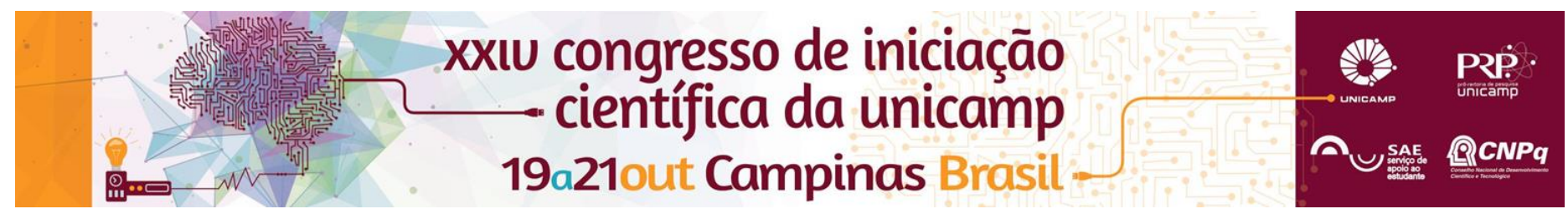

\title{
NEOPLASIAS RENAIS EM RECEPTORES DE TRANSPLANTE RENAL
}

\section{Willian Nishiwaki Alves (IC), Leonardo F Domingues (IC), Marilda Mazzali (orientador)* Resumo}

Tumores de rim nativo são complicações graves em receptores de transplante renal. Uma alternativa terapêutica para estes pacientes é a utilização de imunossupressão com inibidores de mTOR. Neste estudo comparamos pacientes com diagnóstico de neoplasia de rim nativo, tratados com inibidores da mTOR ou mantidos com imunossupressão convencional. Apesar de comparáveis tanto em caracterestícas demográficas como no tipo de neoplasia, os pacientes que utililzaram inibidores da mTOR apresentaram melhor função renal e menor incidência de perda de enxerto durante o período de acompanhamento pós diagnóstico.

Palavras-chave: Transplante renal, neoplasia renal, imunossupressão.

\section{Introdução}

Transplantados renais tem um risco aumentado de neoplasias, comparados com a população geral[1]. Um dos fatores de risco é a utilização de imunossupressores, que inibem o sistema imune hospedeiro, facilitando o implante das células tumorais, bem como a ativação de infecções virais latentes com potencial oncogênico.

Tumores de rim nativo tem maior incidência entre transplantados renais, consequência da transformação maligna da degeneração cística do rim da doença renal crônica ${ }^{[2]}$. Não há consenso sobre a melhor conduta frente a um transplantado renal com neoplasia sólida. Entretanto, para os tumores de rim nativo, os inibidores da mTOR, imunossupressores com efeito anti-proliferativo, podem inibir a replicação de células tumorais, diminuindo recidiva e metástases, mas preservando a função renal.

O objetivo deste estudo foi avaliar a incidência de neoplasias de rim nativo em receptores de transplante renal e o efeito da alteração de imunossupressão para inibidores da mTOR no seu desfecho.

\section{Resultados e Discussão}

Análise retrospectiva de prontuários médicos e do banco de dados do programa de transplante renal do HC UNICAMP.

Critérios de inclusão: transplante renal isolado, idade $\geq 18$ anos, diagnóstico de neoplasia de rim nativo confirmada.

Identificamos 15 pacientes com 16 tumores em rim nativo (1 paciente com neoplasias diagnosticadas em ambos os rins). Para análise, dividimos os pacientes em grupo controle (CTL, $n=7)$, onde a imunossupressão inicial foi mantida após a nefrectomia e grupo mTOR $(n=8)$, que teve a imunossupressão alterada para inibidor da mTOR após o diagnóstico de neoplasia.

O grupos foram comparáveis em relação à distribuição por sexo, faixa etária, tipo de doador, tempo de tratamento dialítico pré transplante, tempo para diagnóstico pós transplante ou valor de creatinina sérica no momento do diagnóstico. O diagnóstico mais frequente foi carcinoma de células claras. Dois pacientes apresentavam tumor metastático, 1 em cada grupo.
Figura 1: Distribuição dos tipos histológicos

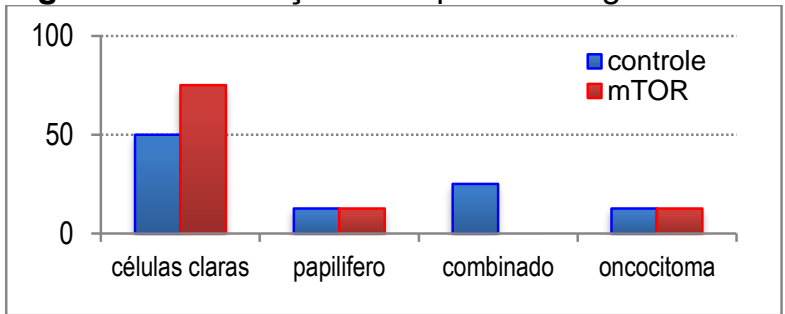

Todos os pacientes foram acompanhados por pelo menos 12 meses após o diagnóstico. Apesar de função renal comparável no momento do diagnóstico, houve, de forma mais precoce, piora progressiva da função renal no grupo controle, com perda de $43 \%$ dos enxertos em média 20,8 meses pós transplante. No grupo mTOR ocorreram 2 perdas de enxerto (25\%), em média 63,0 meses pós transplante. Nos pacientes tratados com inibidor da mTOR, a função renal permaneceu estável durante $\mathrm{O}$ primeiro ano de tratamento, e não foram observados episódios de rejeição aguda com a alteração da imunossupressão.

Figura 2.Evolução da creatinina sérica em 12 meses

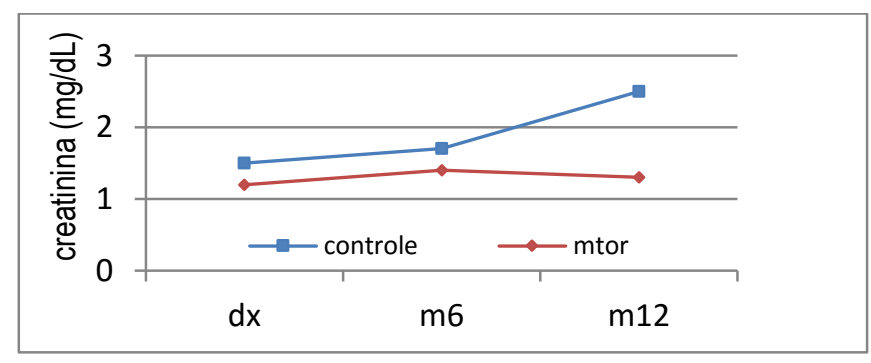

\section{Conclusão}

Nesta série, a utilização de inibidores da mTOR em um grupo de pacientes com diagnóstico de neoplasia renal nos rins primitivos foi segura e proporcionou uma melhor sobrevida, de paciente e enxerto, comparada aos pacientes mantidos sob imunossupressão convencional.

1- Sherston SN, Carrol RP et al. Transplantation 2014; 97:605.

4- Ash WA, Bia MJ. Adv Chronic Kidney Dis 2014; 21(1):106.

5- Dantal J, Soulillou JP.N EngI J Med 2005;352:1371.

6- Euvrard S,Kanitakis J.Transplant Oncol 1998; 3:96 